\title{
Metal Core Bonding Motifs of Monodisperse Icosahedral Au13 and Larger Au Monolayer-Protected Clusters As Revealed by X-ray Absorption Spectroscopy and Transmission Electron Microscopy
}

\author{
Laurent D. Menard \\ Huiping $\mathrm{Xu}$ \\ Follow this and additional works at: https://digitalcommons.fairfield.edu/chemistry-facultypubs \\ Shang-Peng Gao \\ Copyright 2006 American Chemical Society.
}

Ra Pu历le drarticle is also available on the journal site:

http://pubs.acs.org/doijabs/10.1021/jp060740f

Amanda S. Harper-Leatherman

Fairfield University, aharper@fairfield.edu

Peer Reviewed

See next page for additional authors

Repository Citation

Menard, Laurent D.; Xu, Huiping; Gao, Shang-Peng; Twesten, Ray D.; Harper-Leatherman, Amanda S.; Song, Yang; Wang, Gangli; Douglas, Alicia D.; Yang, Judith C.; Frenkel, Anatoly I.; Murray, Royce W.; and Nuzzo, Ralph G., "Metal Core Bonding Motifs of Monodisperse Icosahedral Au13 and Larger Au MonolayerProtected Clusters As Revealed by X-ray Absorption Spectroscopy and Transmission Electron Microscopy" (2006). Chemistry \& Biochemistry Faculty Publications. 7.

https://digitalcommons.fairfield.edu/chemistry-facultypubs/7

\section{Published Citation}

Menard, Laurent D.; Xu, Huiping; Gao, Shang-Peng; Twesten, Ray D.; Harper, Amanda S.; Song, Yang; Wang, Gangli; Douglas, Alicia D.; Yang, Judith C.; Frenkel, Anatoly I.; Murray, Royce W.; Nuzzo, Ralph G. "Metal Core Bonding Motifs of Monodisperse Icosahedral Au13 and Larger Au Monolayer-Protected Clusters As Revealed by X-ray Absorption Spectroscopy and Transmission Electron Microscopy." Journal of Physical Chemistry B, 2006, 110 (30), 14564-14573.

This item has been accepted for inclusion in DigitalCommons@Fairfield by an authorized administrator of DigitalCommons@Fairfield. It is brought to you by DigitalCommons@Fairfield with permission from the rightsholder(s) and is protected by copyright and/or related rights. You are free to use this item in any way that is permitted by the copyright and related rights legislation that applies to your use. For other uses, you need to obtain permission from the rights-holder(s) directly, unless additional rights are indicated by a Creative Commons license in the record and/or on the work itself. For more information, please contact digitalcommons@fairfield.edu. 


\section{Authors}

Laurent D. Menard, Huiping Xu, Shang-Peng Gao, Ray D. Twesten, Amanda S. Harper-Leatherman, Yang

Song, Gangli Wang, Alicia D. Douglas, Judith C. Yang, Anatoly I. Frenkel, Royce W. Murray, and Ralph G.

Nuzzo 


\title{
Metal Core Bonding Motifs of Monodisperse Icosahedral $\mathbf{A u}_{13}$ and Larger $\mathrm{Au}$ Monolayer-Protected Clusters As Revealed by X-ray Absorption Spectroscopy and Transmission Electron Microscopy
}

\author{
Laurent D. Menard, ${ }^{\dagger, \star}$ Huiping Xu, ${ }^{\S}$ Shang-Peng Gao, ${ }^{\S}$ Ray D. Twesten, ${ }^{\ddagger}$ Amanda S. Harper, \\ Yang Song," Gangli Wang," Alicia D. Douglas," Judith C. Yang, ${ }^{\S}$ Anatoly I. Frenkel, ${ }^{\perp}$ \\ Royce W. Murray, *,ll and Ralph G. Nuzzo*,, , \\ School of Chemical Sciences and Frederick Seitz Materials Research Laboratory, University of Illinois, \\ Urbana, Illinois 61801, Department of Materials Science and Engineering, University of Pittsburgh, \\ Pittsburgh, Pennsylvania 15261, Kenan Laboratories of Chemistry, University of North Carolina, \\ Chapel Hill, North Carolina 27599, and Department of Physics, Yeshiva University, \\ New York, New York 10016
}

Received: February 3, 2006; In Final Form: April 18, 2006

\begin{abstract}
The atomic metal core structures of the subnanometer clusters $\mathrm{Au}_{13}\left[\mathrm{PPh}_{3}\right]_{4}\left[\mathrm{~S}\left(\mathrm{CH}_{2}\right)_{11} \mathrm{CH}_{3}\right]_{2} \mathrm{Cl}_{2}(\mathbf{1})$ and $\mathrm{Au}_{13}-$ $\left[\mathrm{PPh}_{3}\right]_{4}\left[\mathrm{~S}\left(\mathrm{CH}_{2}\right)_{11} \mathrm{CH}_{3}\right]_{4}$ (2) were characterized using advanced methods of electron microscopy and X-ray absorption spectroscopy. The number of gold atoms in the cores of these two clusters was determined quantitatively using high-angle annular dark field scanning transmission electron microscopy. Multiplescattering-path analyses of extended X-ray absorption fine structure (EXAFS) spectra suggest that the Au metal cores of each of these complexes adopt an icosahedral structure with a relaxation of the icosahedral strain. Data from microscopy and spectroscopy studies extended to larger thiolate-protected gold clusters showing a broader distribution in nanoparticle core sizes (183 $\pm 116 \mathrm{Au}$ atoms) reveal a bulklike fcc structure. These results further support a model for the monolayer-protected clusters (MPCs) in which the thiolate ligands bond preferentially at 3-fold atomic sites on the nanoparticle surface, establishing an average composition for the MPC of $\mathrm{Au}_{180}\left[\mathrm{~S}\left(\mathrm{CH}_{2}\right)_{11} \mathrm{CH}_{3}\right]_{40}$. Results from EXAFS measurements of a gold(I) dodecanethiolate polymer are presented that offer an alternative explanation for observations in previous reports that were interpreted as indicating $\mathrm{Au} \mathrm{MPC}$ structures consisting of a $\mathrm{Au}$ core, $\mathrm{Au}_{2} \mathrm{~S}$ shell, and thiolate monolayer.
\end{abstract}

\section{Introduction}

The past decade has seen incredible growth in the area of metal and semiconductor nanoparticle research. ${ }^{1-4}$ In the case of metallic nanoparticles, the size regime between 1 and $5 \mathrm{~nm}$ is of extreme interest as this is the range over which the electronic properties of nanoparticles transition from a bulklike continuum of electronic states to molecule-like, discrete electronic orbital levels. ${ }^{1,2,5,6}$ For small nanoparticles, the emergence of nonbulk properties is a complex evolution in which the nanoparticle size, electronic density of states, and structure are strongly intertwined..$^{7-10}$ To develop a fundamental understanding of such complex phenomena requires capacities for materials characterization that are extremely demanding. For example, classifying a metal nanoparticle core by the precise number of metal atoms it contains is far more informative than is a measurement of its apparent diameter in an electron micrograph. ${ }^{11-15}$ Likewise, the characterization of the precise atomiclevel structure of the cluster core and perturbations of that feature as impacted by interactions occurring with ligands, supports, and substrates will serve to powerfully augment understandings

* To whom correspondence should be addressed. E-mail: rwm@unc.edu (R.W.M.), r-nuzzo@uiuc.edu (R.G.N.)

School of Chemical Sciences, University of Illinois.

$\doteqdot$ Frederick Seitz Materials Research Laboratory, University of Illinois.

$\S$ University of Pittsburgh.

" University of North Carolina.

$\perp$ Yeshiva University. of the importance of these parameters with regard to the material's optical, electronic, and chemical properties.

Electron microscopy is an essential tool in the study of nanoparticles since it allows their direct visualization. All the same, there are limitations to the technique that must be considered, especially for clusters whose sizes lie at or below $1 \mathrm{~nm}$. Poor contrast between the smallest metal nanoparticles and the support films on which they are deposited for electron microscopy studies tends to bias microscopic measurements toward any subpopulations of larger sized particles. ${ }^{16,17}$ To overcome this limitation, the present work examines monolayerprotected clusters (MPCs) dispersed on a carbon support using high-resolution measurements augmented by data obtained using the high-angle annular dark field scanning transmission electron microscopy (HAADF-STEM) technique, also know as Zcontrast microscopy. ${ }^{12-15,18,19}$ The latter method collects only the high-angle (typically $>100 \mathrm{mrad}$ ), incoherently scattered electrons, excluding the lower angle Bragg deflections. At these angles, the ratio of the high- $Z /$ low $Z Z$ electron scattering cross sections is significantly greater, thus providing markedly enhanced contrasts for even subnanometer diameter gold clusters. ${ }^{19}$ The exclusion of the Bragg electrons further allows an absolute quantification of the electron scattering cross-section of the individual clusters, a value that can be used to determine the number of metal atoms that it contains. ${ }^{12,13}$ The latter determination, given proper calibrations of the detector response, 
follows simply by dividing the experimentally measured cluster cross section by that of a single high- $Z$ (i.e., gold) atom calculated theoretically using a partial-wave method. ${ }^{12,13}$ These data have been described in detail in an earlier paper. ${ }^{20}$ In this paper, the use of electron microscopy is extended powerfully to embrace a correlated comparison of data obtained using the quantitative HAADF-STEM method with results from highresolution microscopy investigations.

The present work correlates the HAADF-STEM and highresolution transmission electron microscopy (HR-TEM) results with structural understandings elucidated using another technique that has found extensive use in the characterization of nanoparticles, synchrotron X-ray absorption spectroscopy. ${ }^{21-26}$ In this spectroscopic measurement, the structure present at the near-edge region of the absorption spectrum, known as the X-ray absorption near edge structure (XANES), provides information about the density of electronic states above the Fermi level. ${ }^{25,27}$ As a result, the effects of the nanoparticle size and environment on the system's electronic structure can be probed quantitatively. ${ }^{25,28,29}$ The structure of the spectrum $>40 \mathrm{eV}$ above the absorption edge, known as the extended X-ray absorption fine structure (EXAFS), provides a more direct means for determining the nature of the atomic-scale bonding present in the cluster. ${ }^{27,30}$ The local structure probed in this way is typically on the order of $10 \AA$ (determined by the mean free path of the photoelectron) and thus is sufficient to characterize atomic bonding (and occupancies) in metal clusters out to the fifthnearest-neighbor shell. ${ }^{24}$ Bond distances (related to the scattering path lengths) can be resolved with $0.001 \AA$ accuracy, making EXAFS an especially powerful technique for measuring the static and dynamic structural disorder that is highly characteristic of nanoscale systems. ${ }^{23,24,26,31}$

The combined data demonstrate the power of combining X-ray absorption spectroscopy (XAS) and electron microscopy to elucidate the structures of metal-containing nanoscale materials. ${ }^{21-24,32}$ Specifically, we showed that the correlation of multiple-scattering EXAFS analyses with electron microscopy measurements allows the direct characterization of nanoparticle size, shape, and structural disorder even for materials supported in heterogeneous form. ${ }^{24,33,34}$ The present work continues and expands on this methodology to study the structure of ligandprotected gold nanoparticles, useful model clusters that demonstrate well-defined, size-sensitive transitions between metallic and so-called molecular states. ${ }^{5,35-37}$ Given that these materials are explicitly nonbulklike in nature, the correlative use of microscopy is not only useful in augmenting the structural conclusions drawn from XAS methods but also necessary in validating the use of the theoretical terms (scattering path phase and amplitude) calculated for bulk gold and applied to the closepacked Au cluster cores in the EXAFS analysis.

We examine the structures of highly monodisperse $\mathrm{Au}_{13}$ cluster molecules and gold nanoparticle MPCs protected with a thiolate ligand shell. We also describe the XAS characterization of a gold(I) dodecanethiolate polymer, a material that appears to have complicated earlier reports on the nature of MPC ligand shell structures. ${ }^{38,39}$ The current data provide direct evidence that $\mathrm{Au}_{13}$ clusters $(<1 \mathrm{~nm})$ adopt an icosahedral structure while those with average diameters near $2 \mathrm{~nm}$ adopt unrelaxed bonding habits characteristic of the bulk fcc structure.

\section{Experimental Methods}

Gold Cluster Synthesis. The subnanometer clusters $\mathrm{Au}_{13}-$ $\left[\mathrm{PPh}_{3}\right]_{4}\left[\mathrm{~S}\left(\mathrm{CH}_{2}\right)_{11} \mathrm{CH}_{3}\right]_{2} \mathrm{Cl}_{2}(\mathbf{1})$ and $\mathrm{Au}_{13}\left[\mathrm{PPh}_{3}\right]_{4}\left[\mathrm{~S}\left(\mathrm{CH}_{2}\right)_{11} \mathrm{CH}_{3}\right]_{4}$ (2) as well as the larger, fully thiolated Au MPCs were prepared and characterized as described in a separate paper. ${ }^{20}$ All of the nanoparticle samples were prepared by exchanging dodecanethiol onto a parent phosphine halide protected cluster using a modification of literature syntheses. ${ }^{20,35-37}$

Gold(I) Thiolate Polymer Synthesis. The gold(I)thiolate polymer was synthesized by dissolving $1 \mathrm{mmol}$ of $\mathrm{HAuCl}_{4}$ (Strem Chemicals, $99.9 \%$ ) in $50 \mathrm{~mL}$ of THF and then adding 2 mmol of dodecanethiol (Aldrich, 98\%). The solution was stirred until it was colorless and a white solid had precipitated out of solution. The solid was collected on a medium glass frit and washed with $150 \mathrm{~mL}$ of EtOH, dried under vacuum, and collected.

HAADF-STEM Imaging. The imaging protocols used to make these measurements have been described fully in an accompanying paper. ${ }^{20}$ Particles were drop cast from dilute acetone or toluene particle solutions onto TEM grids with an ultrathin carbon film on a holey carbon support (Ted Pella, Inc.). Studies were carried out using a field-emission Vacuum Generators HB501 STEM instrument operated at $100 \mathrm{kV}$. For the collection of annular dark field images the detector was masked, resulting in an inner collection angle of $130 \mathrm{mrad}$. The outer angle of collection was defined by the outer diameter of the ADF detector and by postspecimen compression affected by the objective lens settings and was 520 mrad. ${ }^{40}$ Images were collected at $1 \times$ magnification, and images were $1024 \times 1024$ pixels in dimension. This magnification ensures sufficient sampling of the nanoparticles necessary for the quantitative intensity measurement (the area per pixel is $0.387 \AA^{2}$, and the cluster area is ca. $50 \AA^{2}$ ) while imaging a large number of particles in each image. The detector response as a function of the scattering angle was determined by imaging the masked ADF detector in selected area diffraction mode with an attenuated electron beam current to prevent detector saturation. This calibration allowed calculation of the absolute electron scattering cross sections for individual nanoparticles from the integrated particle intensity in the STEM images. The details of this analysis are described separately. ${ }^{20}$ Using a partial-wave method, the atomic electron scattering cross section for a single gold atom integrated over the experimental collection angles was calculated. ${ }^{20}$ The cluster scattering cross section is linearly related to the number of atoms in the cluster core, and division of the experimentally measured value by the theoretically calculated atomic cross section yielded the number of gold atoms in the cluster cores. ${ }^{13}$

High-Resolution Electron Microscopy. High-resolution electron microscopy was performed using a field-emission JEM $2010 \mathrm{~F}$ (S)TEM instrument operated at $200 \mathrm{kV}$. Image acquisition and analysis was performed using Gatan Digital Micrograph.

XAS Experimental Technique. The X-ray absorption data were measured at beamlines X16C and X11A at the National Synchrotron Light Source at Brookhaven National Laboratory, Upton, NY, and at UNI-CAT beamline 33BM at the Advanced Photon Source at Argonne National Laboratory, Argonne, IL. Measurements were made in transmission mode from $200 \mathrm{eV}$ below to $1700 \mathrm{eV}$ above the $\mathrm{Au} \mathrm{L}_{3}$ edge. The samples were prepared by brushing the nanoparticles onto adhesive tape and stacking layers of the mounted sample until absorption at the $\mathrm{Au} \mathrm{L} \mathrm{L}_{3}$ edge was between 0.5 and 1 . Air-sensitive samples were prepared in a nitrogen glovebox and mounted in an airtight sample cell with Tedlar windows. The samples were then mounted between ion chambers measuring the incident beam intensity $\left(I_{0}\right)$ and transmitted beam intensity $\left(I_{1}\right)$. A gold foil standard was mounted between $I_{1}$ and a reference ion chamber 

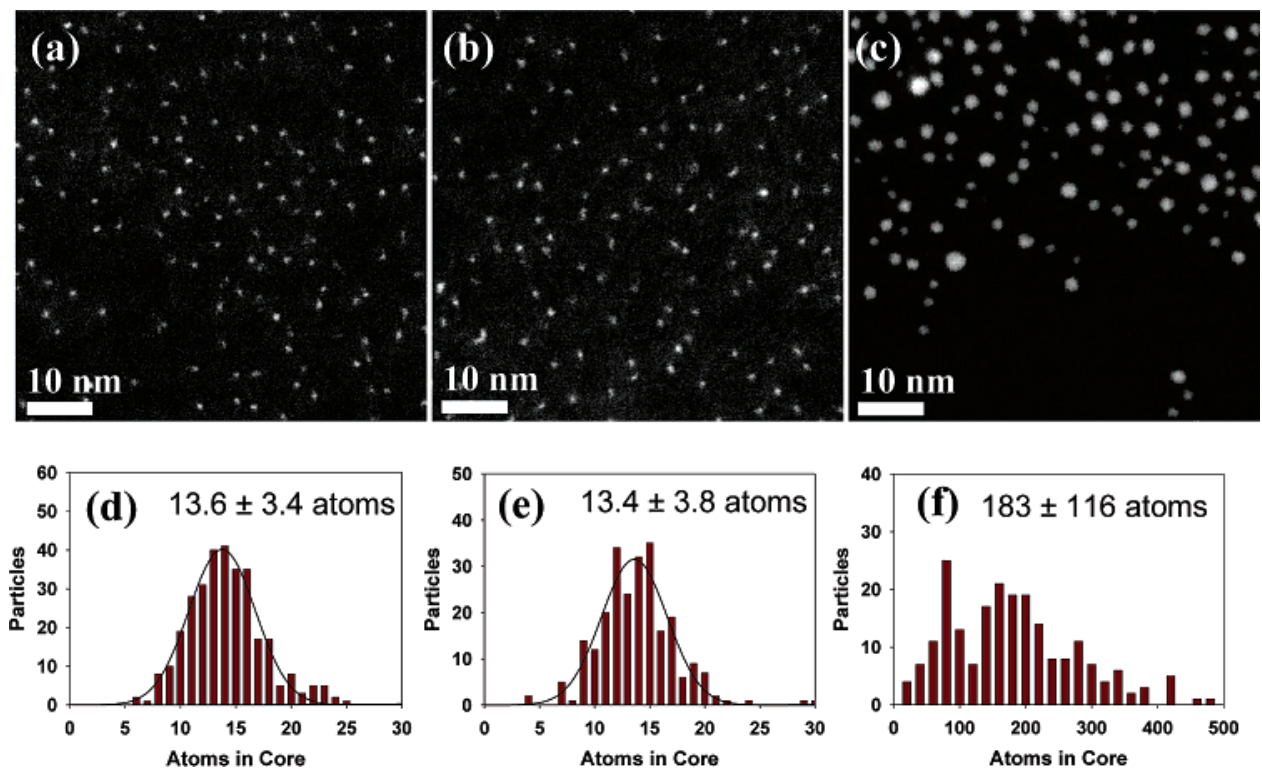

Figure 1. Representative HAADF-STEM images of (a) 1, (b) 2, and (c) thiolate-protected MPCs. All images were collected at $1 \mathrm{M} \times$ magnification. Distribution of core atom counts for gold clusters measured using the quantitative HAADF-STEM technique for $(\mathrm{d}) \mathbf{1}(N=313)$, (e) $\mathbf{2}(N=243)$, and (f) thiolate-protected MPCs $(N=219)$. Gaussian fits to the histograms of $\mathbf{1}$ and $\mathbf{2}$ are provided.

$I_{2}$, and its absorption was measured simultaneously in transmission mode to calibrate the X-ray energy during each scan. Four to five spectra were collected per sample and averaged to improve the signal-to-noise ratio.

EXAFS Analysis. EXAFS data processing and analysis were performed using the IFEFFIT package. ${ }^{41}$ The experimental EXAFS signal, $\chi(k)$, was extracted from the X-ray absorption coefficient data by subtracting the smooth, isolated-atom background function $\mu_{0}(k)$ from the measured signal using the AUTOBK $^{42}$ method:

$$
\chi(k)=\frac{\mu(k)-\mu_{0}(k)}{\Delta \mu_{0}(k)}
$$

where $k=\left[2 m\left(E-E_{0}\right) / \hbar^{2}\right]^{1 / 2}$ is the photoelectron wavenumber, $E$ is the photon energy, and $E_{0}$ is the photoelectron energy origin.

The theoretical multiple-scattering EXAFS signal that is a sum over single-scattering and multiple-scattering photoelectron paths is modeled by the following equation:

$$
\begin{aligned}
\chi(k)=\sum_{i} \frac{S_{0}{ }^{2} N}{k R_{i}{ }^{2}}\left|f_{i}^{\mathrm{eff}}(k)\right| \sin \left[2 k R_{i}-\frac{4}{3} \sigma_{i}^{(3)} k^{3}+\right. \\
\left.\delta_{i}(k)\right] \mathrm{e}^{-2 \sigma_{\mathrm{i}}{ }^{2}{ }^{2}} \mathrm{e}^{-2 R / \lambda_{\mathrm{i}}(k)}
\end{aligned}
$$

where $S_{0}^{2}$ is the passive electron reduction factor, $N_{i}$ is the path degeneracy, equal to the coordination number of neighbors in the $i$ th shell surrounding the absorbing atom $(\mathrm{Au})$ for a singlescattering (SS) path, $R_{i}$ is the effective half path length (which is equal to the interatomic distance for SS paths), $\sigma_{i}^{2}$ is the mean squared relative displacement of $R_{i}$, also known as the EXAFS Debye - Waller factor, $\sigma_{i}^{(3)}$ is the third cumulant of the effective radial pair distribution function that takes into account the anharmonicity of the effective pair potential, and $\lambda_{i}(k)$ is the photoelectron mean free path. ${ }^{24} f_{i}{ }^{\text {eff }}(k)$ and $\delta_{i}(k)$ are the photoelectron scattering amplitude and phase, respectively, of the $i$ th path.

Structural parameters $(\mathrm{Au}-\mathrm{Au}$ and $\mathrm{Au}-\mathrm{S} / \mathrm{P}$ coordination numbers and bond lengths and their mean squared disorders) were obtained by a nonlinear least-squares fit of the theoretical
EXAFS signal to the data in $R$ space by Fourier transforming both the theory and the data. The value of $S_{0}^{2}(0.84 \pm 0.02)$ was obtained from the best fit to the bulk $\mathrm{Au}$ foil data and held fixed in the subsequent fits to the nanoparticle data. Theoretical scattering path amplitudes and phase shifts for all important paths, including multiple-scattering contributions, were calculated for the model $\mathrm{Au}_{2} \mathrm{~S}$ and bulk $\mathrm{Au}$ structures using the FEFF6 code. ${ }^{43}$ It was not possible within the limitations of the present data to distinguish $\mathrm{P}$ from $\mathrm{S}$ within the first-nearestneighbor shell given the similarity of their scattering amplitudes and phases. We therefore modeled the $\mathrm{Au}-\mathrm{S}$ and $\mathrm{Au}-\mathrm{P}$ contributions to the EXAFS data by a theoretical $\mathrm{Au}-\mathrm{S}$ path obtained from the model compound $\mathrm{Au}_{2} \mathrm{~S} .{ }^{44}$ Such an approximation is usually justified by the well-known principle of transferability of photoelectron phase shifts. ${ }^{45}$

We emphasize that the application of this transferability principle to metal nanoparticles - ones that lack the long-range periodicity of the bulk-requires rigorous theoretical justification. Indirect evidence that the bulk photoelectron paths can be successfully used for the nanoparticle analysis, however, stems from the good agreements seen in previous EXAFS and highresolution TEM studies of monodisperse $\mathrm{Pt}$ and $\mathrm{Pt} / \mathrm{Ru}$ nanoparticles as well as recent studies of the relatively less monodispersed thiolate-protected Au nanoparticles. 22,24,34

\section{Results and Discussion}

Quantitative HAADF-STEM. Figure 1 shows representative HAADF-STEM images for $\mathbf{1}, \mathbf{2}$, and the fully thiolated MPCs (parts a, b, and c, respectively, of Figure 1). Such data have been discussed in detail in an earlier paper and explicit correlations made between the apparent cluster diameter (Figure 1) and the atomic compositions of the Au cluster cores. ${ }^{20}$ The high contrast engendered between the high- $Z$ gold particles and the low- $Z$ carbon support is markedly evident in these images. Cluster 1 shows a distribution in the measured core atoms centered at 13.6 atoms with an uncertainty of \pm 3.4 atoms (Figure 1d). Cluster 2 shows a similar result of $13.4 \pm 3.8$ atoms (Figure 1e). The width of these distributions is one that corresponds well to previously determined estimates of the HAADF-STEM instrumental error and errors resulting from 

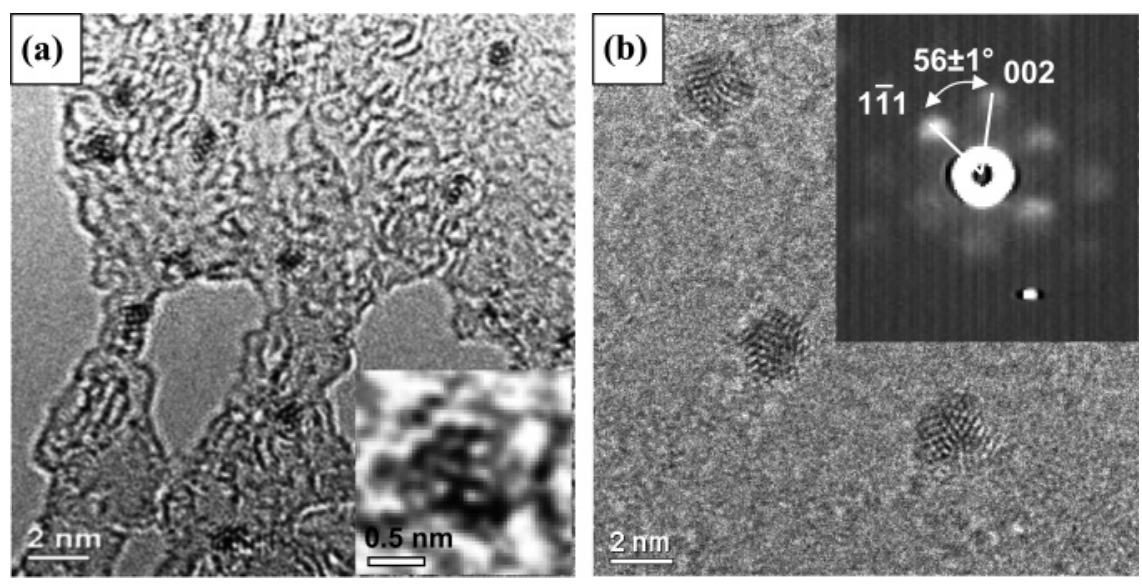

Figure 2. (a) High-resolution electron micrograph of cluster 2. The inset shows a filtered image of a single cluster. (b) Micrograph of thiolateprotected MPCs with cubic packing. The inset shows an indexed microdiffraction image taken from a single particle with a $\sim 2 \mathrm{~nm}$ diameter. See the text for details.

local variations in the carbon film thickness $\left( \pm 3.1\right.$ atoms). ${ }^{13,20}$ This strongly indicates that very little size heterogeneity (ca. \pm 1 atom) is present in the samples of $\mathbf{1}$ and $\mathbf{2}$.

In contrast to the narrow distributions of the subnanometer cluster molecules, the thiolate-protected MPCs display both larger sizes and a broader distribution in the experimentally deduced number of $\mathrm{Au}$ atoms present in the core. The average number of atoms in the core for this sample is $\sim 180$ atoms (corresponding to a diameter of ca. $2 \mathrm{~nm}$ ) with a standard deviation of \pm 116 atoms. The distribution displays what may be local maxima consistent with closed-shell, "magic number" structures (e.g., 79, 140, and 225), as observed in previous studies employing a different, two-phase synthesis introduced by Brust et al. ${ }^{46-50}$

The quantitative HAADF-STEM technique measures the core composition of a statistically significant number of nanoparticles with lower uncertainty than analyses that rely on the determination of nanoparticle diameters. These results provide a set of stiffly constrained limits within which to develop atomic-scale structural models based on EXAFS data, particularly as regards the structure and bonding of the ligand shells that surround these clusters. We discuss this point in more detail below.

High-Resolution Electron Microscopy. High-resolution electron microscopy can be used to develop deep understandings of the atomic-scale structure of nanomaterials. ${ }^{18}$ By way of reference, the structural characterization of larger nanoparticles $(>2 \mathrm{~nm})$ is now routine, with lattice images and diffraction patterns being easily resolved. ${ }^{18}$ These measurements further allow an assessment to be made of any size-varying structural heterogeneity that may be present in a single sample. ${ }^{51} \mathrm{Liu}$, for example, found for a single preparation of gold nanoparticles supported on a carbon substrate a multitude of discrete structural forms. ${ }^{18}$ For particles in the size range of $1-3 \mathrm{~nm}$, these included icosahedral, decahedral, truncated octahedral, and multiply twinned structures. ${ }^{18}$ While high-resolution microscopy provides an information-rich approach to address such complexity on the level of single nanoparticles, it remains difficult to develop predictive statistics, and as a result the relative abundances of such varied structural habits are hard to quantify. More importantly, the measurement itself can impact results due to electron-beam-induced structural changes of nanoparticles during the experiment. ${ }^{16,18,52}$ These issues are particularly important for nanoparticles that are $<2 \mathrm{~nm}$ in diameter because of the greater potential they hold for interconversion between different structural motifs-ones separated via modest energy barriers-and the consequent acceptance of a number of metastable structures. $8,9,53,54$

Figure 2 a presents a representative high-resolution electron micrograph of a sample of cluster 2. The inset of Figure 2a shows a representative filtered image of a single $\mathrm{Au}_{13}$ nanoparticle with interatomic distances of $\sim 2.8 \pm 0.1 \AA$. The HRTEM and the HAADF-STEM results (viz., cluster diameters and atom count) strongly suggest that the $\mathrm{Au}_{13}$ clusters possess closed-shell core structures; we are not able to make a definitive structural assignment of cuboctahedral or icosahedral packing on the basis of these data alone however (the image quality and concerns regarding beam-induced decomposition preclude it). Related phosphine halide ligated $\mathrm{Au}_{13}$ clusters have been previously prepared and characterized with X-ray diffraction and found to possess icosahedral structure. ${ }^{55-61}$ In fact, a large number of phosphine halide gold clusters (ones with cores of 9-13 atoms) have been shown to assume icosahedral or pseudoicosahedral structures. ${ }^{58-61}$ Such icosahedral structural behavior stands in contrast to that seen in larger clusters, for which fcc structures are expected to dominate. $6,47,48$

Figure $2 b$ shows a representative micrograph of larger thiolate-protected MPCs that demonstrates this point. The cubic close-packed structure of the MPCs is clearly evident in the real space images and inset diffraction image taken from a single nanoparticle. The $\mathrm{Au}-\mathrm{Au}$ distance determined using this diffraction data was found to be $2.8 \pm 0.1 \AA$. This compares well to the results of structural characterizations made of thiolate-protected nanoparticles prepared via the Brust and Schiffrin two-phase synthesis. ${ }^{48}$ By way of comparison, the nearest-neighbor bonding distance present in the bulk fcc structure is $2.884 \AA .{ }^{62}$ We note that over the experimental time scales of the HR-TEM imaging of these fcc clusters there were no observed shape or structure changes induced by electronbeam irradiation.

XANES. The XANES region of the X-ray absorption spectrum provides information about the density of states above the Fermi level. The first resonance at the absorption edge is referred to as the "white line" and corresponds to the $2 \mathrm{p}_{3 / 2} \rightarrow$ $5 \mathrm{~d}_{5 / 2,3 / 2}$ dipole transitions at the $\mathrm{L}_{3}$ edge. ${ }^{25,26,28,63,64}$ For transition metals with vacant d-orbitals this resonance is a sharp peak. ${ }^{28}$ In the case of $\mathrm{Au}$, the d-orbitals are nominally filled, and therefore, no transitions are expected. Hybridization of the $5 \mathrm{~d}$ orbitals with the overlapping $6 \mathrm{~s}$ and $6 \mathrm{p}$ orbitals, however, results in a small population of about $0.45 \mathrm{~d}$-hole shifted above the Fermi level. ${ }^{25,63,64}$ One also expects that cluster-size-dependent patterns of ligand binding, and support interactions, would affect 


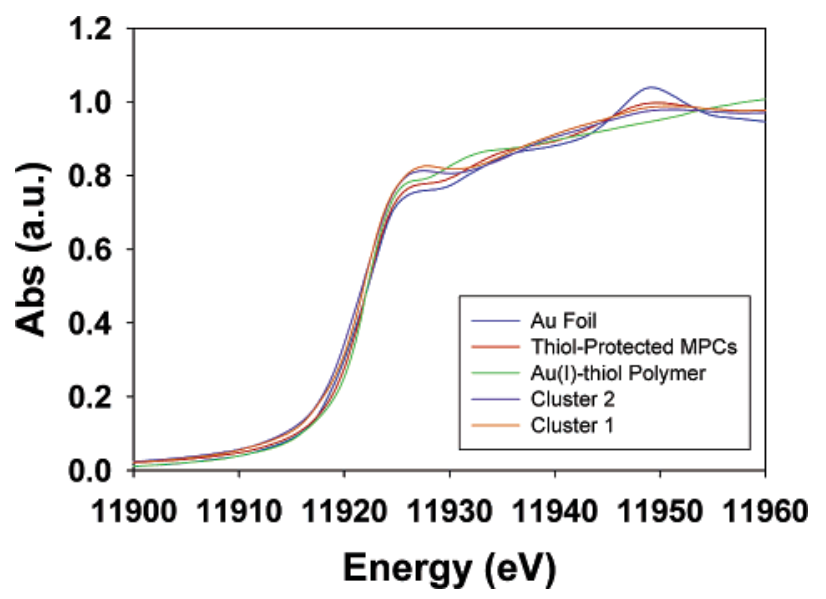

Figure 3. XANES region of the $\mathrm{Au} \mathrm{L}_{3}$ absorption edge for the $\mathrm{Au}$ foil standard, 1, 2, thiolate-protected MPCs, and the gold(I) dodecanethiolate polymer.

these occupancies. For example, earlier work by Zhang and Sham shows that $2 \mathrm{~nm}$ gold particles protected with thiolate ligands exhibit a greater white line intensity than identically sized particles capped with weakly interacting dendrimers - an effect due to charge transfer from the gold core to the more electronegative ligands. ${ }^{64}$ The effects are most dramatic for the smallest particles due to their greater surface-area-to-volume ratios. $^{25}$

Figure 3 provides a comparison of data measured in the XANES region for the two $\mathrm{Au}_{13}$ cluster molecules (1 and 2), the thiolate-protected MPC sample, and a gold(I) dodecanethiolate polymer, along with that of a Au foil standard. The thiolateprotected MPC sample shows a slight increase in the white line intensity relative to that of the Au foil, an observation indicative of a slightly increased population of d-holes being present in the former material due to the electron-withdrawing effect of the electronegative thiolate ligands. ${ }^{25}$ The structure in the spectrum at energies $>10 \mathrm{eV}$ above the absorption edge for this sample shows the same oscillations (part of the fine structure) as the Au foil but with significant broadening. This suggests a bulklike fcc structure for the Au MPCs, albeit with lower coordination numbers and greater disorder than those of the foil standard, a conclusion validated by the EXAFS analysis presented below. ${ }^{24}$

Clusters 1 and $\mathbf{2}$ show the greatest white line intensities of the samples studied, illustrating the size-dependent impact of charge transfer on the metal cores. That is, the partial positive charge on the clusters resulting from charge transfer to the ligands is distributed over fewer $\mathrm{Au}$ atoms, resulting in a greater increase in the d-hole population above the Fermi level relative to that of the larger MPCs. Cluster 1 shows a slightly higher intensity, suggesting a greater d-hole population (i.e., greater positive charge character). This is supported by XPS measurements that show a shift to higher binding energies in the Au $4 \mathrm{f}$ region for cluster $\mathbf{1}(84.4 \mathrm{eV})$ while the binding energy for cluster 2 is that of the bulk metal $(84.0 \mathrm{eV}) .{ }^{20}$ Such a shift indicates an increase in the oxidation state of the $\mathrm{Au}$ in cluster $\mathbf{1}$, likely resulting from the presence of the highly electronegative chloride ligands. ${ }^{65}$ Some caution is warranted here, however, as the contributions of final state effects are expected to be important for clusters of this size and might obscure explicit correlations with formal oxidation states. ${ }^{66,67}$ The fine structure seen for clusters $\mathbf{1}$ and $\mathbf{2}$ at energies $>10 \mathrm{eV}$ above the edge is characterized by broader oscillations and a shift in peak positions relative to those of both the $\mathrm{Au}$ foil standard and the larger $\mathrm{Au}$
MPCs, indicating smaller cluster sizes and structures differing from the fcc bulk structure.

The gold(I) dodecanethiolate polymer exhibits a white line of intermediate intensity relative to that of the bulk foil and cluster samples despite the fact that there is a formal +1 charge on the $\mathrm{Au}$ atom. ${ }^{20,47}$ As indicated in the discussion above, the white line intensity depends not only on the valency of the absorbing atom but also on the hybridization of its valence orbitals. Formalisms based on the metallic band structure that are convenient for understanding transitions at the absorption edge for clusters and nanoparticles become inadequate, and theoretical calculations are needed to provide deeper insight into this aspect of the electronic structure. ${ }^{26,63}$ In the present context we simply note that the fine structure above the edge for the gold(I) dodecanethiolate polymer clearly shows very different structure compared to that of either the Au foil or any of the small Au clusters described here.

Multiple-Scattering EXAFS Analysis of $\mathbf{A u}_{13}$ Clusters. The EXAFS data for $\mathrm{Au}_{13}$ nanoparticles were fit using multiplescattering paths according to protocols described elsewhere. ${ }^{24,33}$ The fitting was performed in real space on Fourier-transformed data ( $k=3-12 \AA^{-1}, R=1.4-4.6 \AA, k^{2}$ weighting) using the scattering paths illustrated in Figure $4 \mathrm{a}$. The paths used include the $\mathrm{Au}-\mathrm{S}$ single-scattering ( $\mathrm{SS} 1), \mathrm{Au}-\mathrm{Au}$ first-nearest-neighbor single-scattering (SS1), second-nearest-neighbor single-scattering (SS2), third-nearest-neighbor single-scattering (SS3), and relevant high-symmetry triangular multiple-scattering (TR) paths. ${ }^{24}$ The diagram shows model structures for icosahedral and cuboctahedral $\mathrm{Au}_{13}$ nanoparticles on which these atomic pairs are overlaid. Of particular note is the fact that the coordination shell corresponding to the second-nearest-neighbor (SS2) distance in the ideal, bulk fcc structure (4.08 $\AA$ ) is absent in the icosahedral cluster. The analysis of the EXAFS data discussed below shows that this scattering contribution, one expected to produce a peak between 3 and $4 \AA$, in fact is not present for clusters $\mathbf{1}$ and $\mathbf{2}$, providing strong evidence that, in each case, the structure adopted is likely icosahedral.

The Fourier-transformed data and the best fit results for the $\mathrm{Au}_{13}$ clusters are shown in Figure 4b,c. The results for the parameters varied in the EXAFS fitting analysis are given in Table 1, along with theoretical values calculated for the two model structures listed for purposes of comparison. With respect to the $\mathrm{Au}-\mathrm{Au}$ scattering paths, the results for cluster $\mathbf{1}$ and cluster $\mathbf{2}$ are indistinguishable, indicating an identical metal core structure (at least to within the resolution of the measurement). The coordination numbers for the $\mathrm{Au}-\mathrm{Au}$ first-nearest-neighbor single-scattering paths are consistent with an icosahedral cluster $\left(N_{\mathrm{SS} 1}=6.46\right)$, while showing no overlap to within the uncertainties with the value expected for a cuboctahedral cluster $\left(N_{\mathrm{SS} 1}=5.54\right)$. The contributions of slightly larger cuboctahedral clusters (as potential impurities) to these measured values of $\mathrm{Au}-\mathrm{Au}$ first-shell coordination numbers, ones that would result in an erroneous and larger value of $N_{\mathrm{SS} 1}$, can be discounted since the quantitative HAADF-STEM measurements show the absence of such clusters. The extraordinary size homogeneity indicated by the microscopy strongly implies that the spectroscopically determined structure parameters derive from clusters of a single core nuclearity and do not represent an ensemble of many different core sizes.

The first-nearest-neighbor distance $\left(R_{\mathrm{SS} 1}=2.83 \pm 0.01 \AA\right)$ shows a significant contraction from the bulk value of $2.88 \AA$; this is expected for small clusters where such contractions are described qualitatively in terms of particle surface tension or, more precisely, in terms of the bonding impacts of vacancies 
(a)

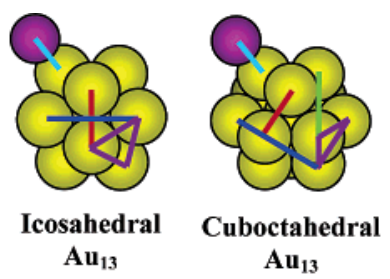

Cluster 1

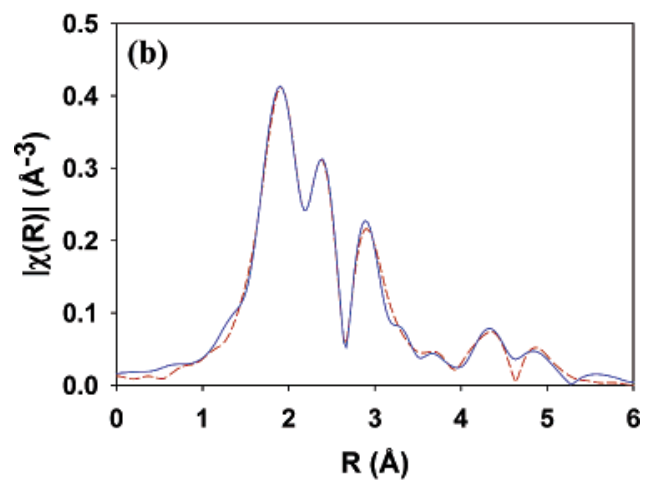

Cluster 2

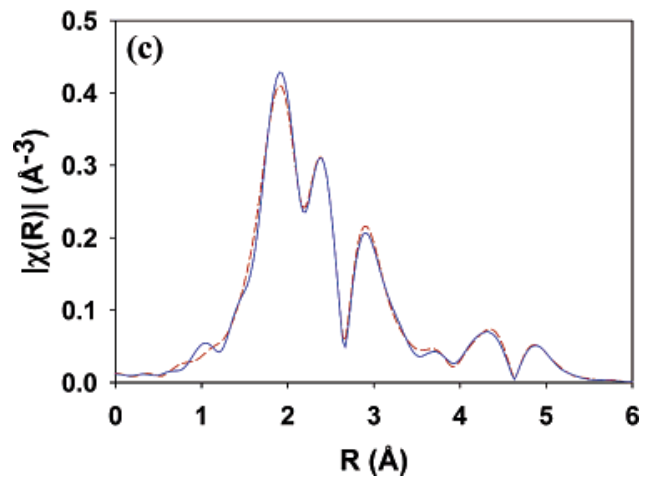

Figure 4. (a) Diagram of scattering paths used in the multiplescattering-path EXAFS fits: (light blue line) $\mathrm{Au}-\mathrm{S} \mathrm{SS1}$, (red line) $\mathrm{Au}-\mathrm{Au} \mathrm{SS1}$, (green line) $\mathrm{Au}-\mathrm{Au} \mathrm{SS} 2$, (purple line) $\mathrm{Au}-\mathrm{Au} \mathrm{TR}$, (dark blue line) $\mathrm{Au}-\mathrm{Au}$ SS3. FT magnitude plots of the EXAFS data (solid blue line) and full multiple-scattering-path fit (dashed red line) for (b) cluster 1 and (c) cluster 2.

in the d-shell on the clusters' metal-metal bonding.7,68 This contracted bond length can be used to perform a geometrical calculation of the third-nearest-neighbor single-scattering half path length. In the case of a cuboctahedral 13-atom cluster, one would expect a half path length for SS3 of $4.90 \AA\left(R_{\mathrm{SS} 3}=\right.$ $\left.(\sqrt{ } 3) R_{\mathrm{SS} 1}\right)$. This is greater than the experimentally determined value of $4.75 \AA$. In the case of a 13-atom icosahedral cluster, the presence of icosahedral strain compresses the distance further. ${ }^{8,26,69}$ To achieve close-packing of the surface atoms in a 13-atom icosahedron, the bond distances between atoms on the surface of the cluster must be 5\% longer than the distances between the surface atoms and the central atom..$^{69,70}$ Taking this $5 \%$ strain into consideration, the SS3 path length expected for the icosahedral structure would be $4.65 \AA$. This is shorter than the $4.75 \AA$ measured path length. In fact, the path length reported corresponds to a strain of ca. 3\%. Clearly then, the presence of the ligands on the cluster surface must lead to a relaxation of the icosahedral strain. 7,68

These fits include the use of the third cumulant, which for a contribution from the same shell of atoms serves to quantify the anharmonicity of the effective pair potential. ${ }^{24}$ While the icosahedral splitting is confirmed experimentally through an analysis of the first- and third-nearest-neighbor scattering path lengths, only a single $\mathrm{Au}-\mathrm{Au}$ first-neighbor path is used in the fit given that the range of EXAFS data is insufficient to resolve the two first-neighbor distances that differ by $\Delta R \approx 0.1 \AA$ (which corresponds to an icosahedral split of 3\%). To resolve this splitting, which would be evident as a beat in $k$ space at $\pi /(2 \Delta R)=16 \AA^{-1}$, the data would have to be analyzed well beyond $16 \AA^{-1} .{ }^{27}$ In our case, that region of the EXAFS spectrum is dominated by noise. For this reason, the effect of the splitting cannot be distinguished from a single shell having enhanced disorder (which can be modeled in a quasi-Gaussian approximation with the Debye-Waller factor and a third cumulant). The implication in fitting the first-nearest-neighbor path with one effective single-scattering path is that the DebyeWaller factor and third cumulant are increased because these fit parameters compensate for the broad and asymmetric distribution of atomic distances in the icosahedral structure. The values for the third cumulant reported in Table 1, therefore, are a convolution of the pair potential asymmetry and the asymmetric bond length distributions. The stability of these fits was verified by performing them both with and without the third cumulant. In the latter case, the only value that changed significantly was the first-nearest-neighbor scattering path length, as is expected given the correlations that exist between the third cumulant and scattering path length. ${ }^{24}$ Irrespective of any changes in this path length due to fitting parameters, however, a comparison between the first and third scattering path lengths was always consistent with an icosahedral strain of $2.5-3.5 \%$.

We turn now to a consideration of ligand shells that serve to stabilize $\mathrm{Au}_{13}$ cores in $\mathbf{1}$ and $\mathbf{2}$. Although the clusters are protected by a mixed ligand shell of phosphines and thiolates, only a single $\mathrm{Au}-\mathrm{S}$ scattering path was used to fit the $\mathrm{Au}$ low- $Z$ scattering paths (with FEFF-calculated phase and amplitude generated using a $\mathrm{Au}_{2} \mathrm{~S}$ model) ${ }^{44}$ This was done to reduce the number of variables in the fit, and the assumption (of nearly equivalent scattering amplitudes and phases for $\mathrm{Au}-\mathrm{S}, \mathrm{Au}-\mathrm{P}$, and $\mathrm{Au}-\mathrm{Cl}$ paths) was checked by performing the fits using solely $\mathrm{Au}-\mathrm{P}$ and then $\mathrm{Au}-\mathrm{Cl}$ scattering path amplitudes and phases calculated with FEFF from the crystallographic atomic positions of $\mathrm{Ph}_{3} \mathrm{PAuCl} .{ }^{71}$ No significant changes in the values of the fit parameters were observed, and the choice to use the $\mathrm{Au}-\mathrm{S}$ scattering path was therefore adopted. For both clusters, the $\mathrm{Au}-\mathrm{S}$ coordination numbers (a composite of $\mathrm{Au}-\mathrm{S}, \mathrm{Au}-$ $\mathrm{P}$, and $\mathrm{Au}-\mathrm{Cl}$ bonding) indicate that not all of the surface atoms are bonded to a ligand. The value of $0.83 \pm 0.07$ for cluster 1 is consistent with $10-11$ of the 12 surface Au atoms being bonded to a ligand. Given the experimentally determined

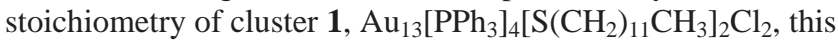
suggests a model for the ligand bonding in which the four phosphines and two chlorides are singly bound at on-top sites to $\mathrm{Au}$ surface atoms (a bonding motif rigorously characterized in phosphine halide clusters) and the thiolates are bound at bridge sites. ${ }^{20,59,61,72-74}$ Cluster $2, \mathrm{Au}_{13}\left[\mathrm{PPh}_{3}\right]_{4}\left[\mathrm{~S}\left(\mathrm{CH}_{2}\right)_{11} \mathrm{CH}_{3}\right]_{4}$, shows a slightly lower surface coordination $(0.76 \pm 0.05)$ consistent with $9-10$ of the surface atoms being bonded to a ligand. This clearly invalidates a model in which all four thiolates exhibit an identical bridge-site bonding nature, one in which all surface atoms would be coordinated to a ligand and $N(\mathrm{Au}$ low-Z) would be 0.92 . A model in which two of the thiolates are bound at on-top sites, similar to the chlorides in cluster 1, is consistent with the experimental results.

Multiple-Scattering EXAFS Analysis of Larger, ThiolateProtected MPCs. The examination of the $\mathrm{Au}_{13}$ model systems 
TABLE 1: EXAFS Fitting Results for 1 and 2 Compared to Ideal 13-Atom Icosahedral and Cuboctahedral Clusters

\begin{tabular}{|c|c|c|c|c|}
\hline $\begin{array}{c}\text { fitting } \\
\text { parameter }\end{array}$ & cluster 1 & cluster 2 & $\begin{array}{l}\text { ideal } \mathrm{Au}_{13} \\
\text { icosahedron }\end{array}$ & $\begin{array}{c}\text { ideal } \mathrm{Au}_{13} \\
\text { cuboctahedron }\end{array}$ \\
\hline$N_{\mathrm{SS} 1}(\mathrm{Au}-\mathrm{S})$ & $0.83 \pm 0.08$ & $0.76 \pm 0.07$ & & \\
\hline$R_{\mathrm{SS} 1}(\mathrm{Au}-\mathrm{S}), \AA$ & $2.310 \pm 0.007$ & $2.324 \pm 0.007$ & & \\
\hline$\sigma_{\mathrm{SS}^{2}}(\mathrm{Au}-\mathrm{S}), \AA^{2}$ & $0.005 \pm 0.001$ & $0.003 \pm 0.001$ & & \\
\hline$N_{\mathrm{SS} 1}(\mathrm{Au}-\mathrm{Au})$ & $6.2 \pm 0.6$ & $6.7 \pm 0.7$ & 6.46 & 5.54 \\
\hline$R_{\mathrm{SS} 1}(\mathrm{Au}-\mathrm{Au}), \AA$ & $2.83 \pm 0.01$ & $2.85 \pm 0.02$ & 2.83 & 2.83 \\
\hline$\sigma_{\mathrm{Ss} 1}{ }^{2}(\mathrm{Au}-\mathrm{Au}), \AA^{2}$ & $0.014 \pm 0.001$ & $0.015 \pm 0.001$ & & \\
\hline$\sigma_{\mathrm{SS} 1}{ }^{(3)}(\mathrm{Au}-\mathrm{Au}), \AA^{3}$ & $0.0003 \pm 0.0005$ & $0.0006 \pm 0.0004$ & & \\
\hline$N_{\mathrm{TR}}(\mathrm{Au}-\mathrm{Au})$ & $34 \pm 26$ & $21 \pm 8$ & 23.08 & 14.77 \\
\hline$R_{\mathrm{TR}}(\mathrm{Au}-\mathrm{Au}), \AA$ & $4.24 \pm 0.05$ & $4.26 \pm 0.03$ & 4.25 & 4.25 \\
\hline$\sigma_{\mathrm{TR}}^{2}(\mathrm{Au}-\mathrm{Au}), \AA^{2}$ & $0.01 \pm 0.02$ & $0.01 \pm 0.01$ & & \\
\hline$N_{\mathrm{SS} 3}(\mathrm{Au}-\mathrm{Au})$ & $8 \pm 6$ & $8 \pm 4$ & 4.62 & 3.69 \\
\hline$R_{\mathrm{SS} 3}(\mathrm{Au}-\mathrm{Au}), \AA$ & $4.75 \pm 0.03$ & $4.75 \pm 0.02$ & 4.65 (5\% strain) & 4.90 \\
\hline$\sigma_{\mathrm{SS} 3}{ }^{2}(\mathrm{Au}-\mathrm{Au}), \AA^{2}$ & $0.017 \pm 0.007$ & $0.017 \pm 0.005$ & & \\
\hline
\end{tabular}

TABLE 2: EXAFS Fitting Results for Thiolate-Protected MPCs

\begin{tabular}{llll}
\hline \multicolumn{1}{c}{ parameter } & \multicolumn{1}{c}{$\begin{array}{c}\text { fully } \\
\text { thiolated NP }\end{array}$} & \multicolumn{1}{c}{ parameter } & \multicolumn{1}{c}{$\begin{array}{c}\text { fully } \\
\text { thiolated NP }\end{array}$} \\
\hline$N_{\mathrm{SS} 1}(\mathrm{Au}-\mathrm{S})$ & $0.7 \pm 0.1$ & $R_{\mathrm{SS} 2}(\mathrm{Au}-\mathrm{Au}), \AA$ & $4.01 \pm 0.02$ \\
$R_{\mathrm{SS} 1}(\mathrm{Au}-\mathrm{S}), \AA$ & $2.310 \pm 0.005$ & $\sigma_{\mathrm{SS} 2}(\mathrm{Au}-\mathrm{Au}), \AA^{2}$ & $0.016 \pm 0.009$ \\
$\sigma_{\mathrm{SS} 1}{ }^{2}(\mathrm{Au}-\mathrm{S}), \AA^{2}$ & $0.001 \pm 0.001$ & $N_{\mathrm{TR}}(\mathrm{Au}-\mathrm{Au})$ & $35 \pm 18$ \\
$N_{\mathrm{SS} 1}(\mathrm{Au}-\mathrm{Au})$ & $8.9 \pm 0.5$ & $R_{\mathrm{TR}}(\mathrm{Au}-\mathrm{Au}), \AA$ & $4.25 \pm 0.02$ \\
$R_{\mathrm{SS} 1}(\mathrm{Au}-\mathrm{Au}), \AA$ & $2.83 \pm 0.01$ & $\sigma_{\mathrm{TR}}{ }^{2}(\mathrm{Au}-\mathrm{Au}), \AA^{2}$ & $0.01 \pm 0.01$ \\
$\sigma_{\mathrm{SS} 1}{ }^{2}(\mathrm{Au}-\mathrm{Au}), \AA^{2}$ & $0.013 \pm 0.001$ & $N_{\mathrm{SS} 3}(\mathrm{Au}-\mathrm{Au})$ & $9 \pm 3$ \\
$\sigma_{\mathrm{SS} 1}{ }^{(3)}(\mathrm{Au}-\mathrm{Au}), \AA^{3}$ & $0.0002 \pm 0.0002$ & $R_{\mathrm{SS} 3}(\mathrm{Au}-\mathrm{Au}), \AA$ & $4.91 \pm 0.02$ \\
$N_{\mathrm{SS} 2}(\mathrm{Au}-\mathrm{Au})$ & $3 \pm 2$ & $\sigma_{\mathrm{SS} 3}{ }^{2}(\mathrm{Au}-\mathrm{Au}), \AA^{2}$ & $0.014 \pm 0.005$
\end{tabular}

described above demonstrates the capabilities of advanced electron microscopy and X-ray absorption spectroscopy to provide a wealth of complementary structural information. This methodology is extended to a system showing a greater distribution in nanoparticle core sizes to further illustrate the utility of correlating HAADF-STEM and XAS results in structural characterizations of MPCs of the type that are attracting significant interest in current research. ${ }^{4,47,48,75,76}$ Figure 5 presents the Fourier-transformed data and the best fit results for the thiolate-protected MPC material $\left(k=3-12 \AA^{-1}, R=\right.$ 1.4-4.6 $\AA$, $k^{2}$ weighting). The scattering paths used in the fitting analysis are identical to those employed in the $\mathrm{Au}_{13}$ fits, with the exception that the second-nearest-neighbor single-scattering path was now clearly required to develop an acceptable fit to the data. The contribution from this scattering path is indicated by the arrow overlaid in the figure. The fitting results are presented in Table 2.

Similar to the results seen for the $\mathrm{Au}_{13}$ clusters, the thiolateprotected clusters show a contraction in $\mathrm{Au}-\mathrm{Au}$ bond length $(2.83 \pm 0.01 \AA)$ from the bulk value $(2.88 \AA) .{ }^{62}$ To correlate the EXAFS results with structural understandings developed

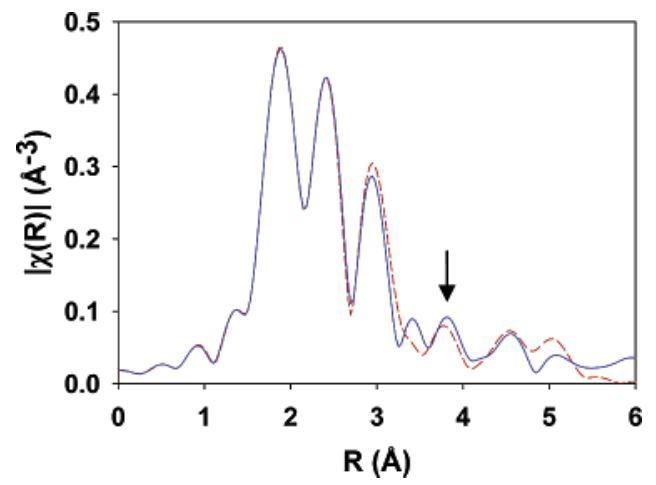

Figure 5. FT magnitude plots of the EXAFS data (solid blue line) and full multiple-scattering-path fit (dashed red line) for thiolateprotected MPCs. The arrow marks the increased magnitude (compared to that of $\mathrm{Au}_{13}$ clusters) from the SS2 contribution. from microscopy, both high-resolution TEM and HAADFSTEM studies of the MPCs were carried out. The former data firmly established the fcc pseudospherical structure of these particles (Figure 2). These data can be understood in more detail in the context of a structural model based on a truncated octahedral core. On the basis of this assumption, we constructed a plot of the calculated first-nearest-neighbor single-scattering coordination number as a function of the number of atoms in the cluster (Figure 6a) for closed-shell clusters $(6,38,79,140$, etc. atoms), interpolating the plot for clusters without a closed shell of atoms. Similarly, the number of surface atoms, again calculated as a function of total atoms in the model clusters, was plotted (Figure 6a). The plot in Figure 6b shows an analysis of the MPC system made using the HAADF-STEM measurement. In this plot, the histogram shows a statistical sampling of the atom counts established on a cluster by cluster basis. A comparison made with the plots of Figure $6 \mathrm{a}$ proves to be particularly informative. We can, for example, calculate a weighted average for $N_{\mathrm{SS} 1}$ and the percentage of atoms that are on the surface for a cluster corresponding to the averages of the HAADF-STEM cluster atom count data. The average $N_{\mathrm{SS} 1}$ value calculated in this way was 9.39, a result in excellent agreement with the EXAFS-determined value $(8.9 \pm 0.5)$. While
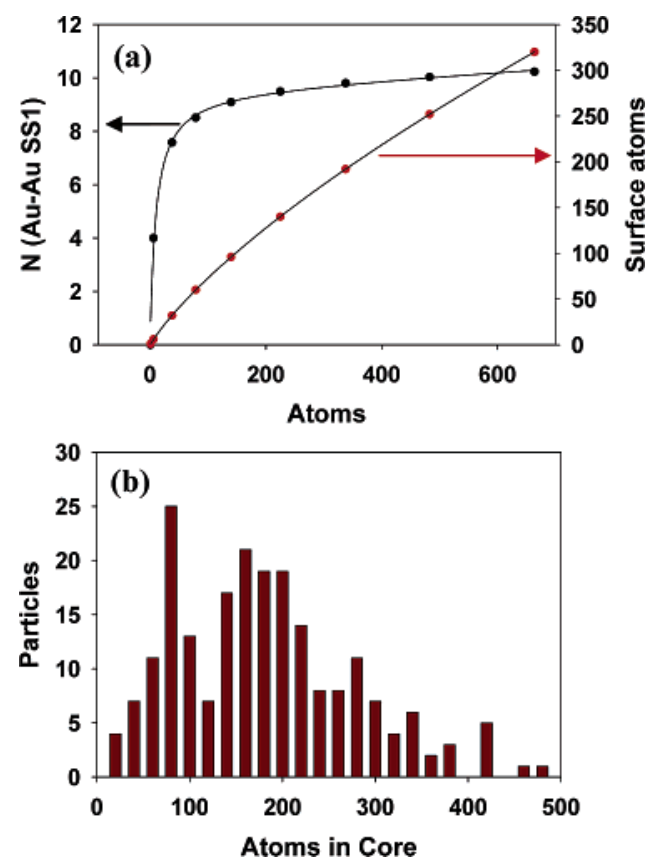

Figure 6. (a) Theoretical first-nearest-neighbor single-scattering coordination numbers and number of surface atoms for truncated octahedral clusters. (b) Histogram showing the distribution of thiolateprotected cluster core atom counts determined from HAADF-STEM. 
TABLE 3: EXAFS Fitting Results for the Gold(I) Dodecanethiolate Polymer

\begin{tabular}{llcll}
\hline parameter & $\begin{array}{c}\text { gold thiolate } \\
\text { polymer }\end{array}$ & $\begin{array}{c}\text { linear chain } \\
\text { model }\end{array}$ & \multicolumn{1}{c}{ parameter } & $\begin{array}{c}\text { gold thiolate } \\
\text { polymer }\end{array}$ \\
\hline$N_{\mathrm{SS} 1}(\mathrm{Au}-\mathrm{S})$ & $2.0 \pm 0.1$ & 2 & $N_{\mathrm{TS}}(\mathrm{Au}-\mathrm{S})$ & $1.8 \pm 0.9$ \\
$R_{\mathrm{SS} 1}(\mathrm{Au}-\mathrm{S}), \AA$ & $2.298 \pm 0.004$ & & $R_{\mathrm{TS}}(\mathrm{Au}-\mathrm{S}), \AA$ & $5.0 \pm 0.1$ \\
$\sigma_{\mathrm{SS} 1}(\mathrm{Au}-\mathrm{S}), \AA^{2}$ & $0.0019 \pm 0.0004$ & & $\sigma_{\mathrm{TS}}{ }^{2}(\mathrm{Au}-\mathrm{S}), \AA^{2}$ & $0.004 \pm 0.004$
\end{tabular}

the change in the $\mathrm{Au}-\mathrm{Au}$ first-nearest-neighbor coordination number over the range of cluster sizes in this sample is relatively small ( $87 \%$ of the particles with $N_{\mathrm{SS} 1}$ between 8.5 and 10.5) and the agreement between the STEM-determined coordination number and the EXAFS-measured value is therefore somewhat unremarkable, the strong variation in the percentage of surface atoms with particle size provides a powerful, second metric for assessing the qualities of the microscopy-spectroscopy structural correlations. Consider, in this regard, the fact that the average weighted fraction of gold atoms on the surface of the MPC nanoparticle cores is estimated from these data to be $\sim 0.62$. This value can be correlated directly to the EXAFS results for the nature of the $\mathrm{Au}-\mathrm{S}$ scattering since, in this case, the thiolate ligands are surface species. The EXAFS-determined value for $N(\mathrm{Au}-\mathrm{S})$ was $0.7 \pm 0.1$. The excellent $1: 1$ agreement between the percentage of Au atoms on the cluster surface and the $\mathrm{Au}-\mathrm{S}$ coordination number suggests that each gold atom on the surface is coordinated to a single sulfur atom. If the three bonding models for thiolate adsorption are considered (bonding at 3-fold sites, bridge sites, or on-top sites), then the following expected values for the $\mathrm{S}: \mathrm{Au}$ average composition are obtained: 3 -fold sites, $N(\mathrm{Au}-\mathrm{S}) / 3=0.23$; bridge sites, $N(\mathrm{Au}-$ $\mathrm{S}) / 2=0.35$; on-top sites, $N(\mathrm{Au}-\mathrm{S})=0.7$. These values are quite informative given that the $\mathrm{S}$ :Au composition (determined experimentally with XPS) for this sample of MPCs was $0.22 .{ }^{20}$ This strongly supports a model of the cluster structure in which the thiolate ligands bond preferably to the gold surface at 3-fold sites, in contrast to the bonding in the smaller, $\mathrm{Au}_{13}$ icosahedral clusters. Although the low-defect structure of two-dimensional SAMs is generally accepted to be a $(\sqrt{ } 3 \times \sqrt{ } 3)$ structure, debate remains as to whether the thiolates sit at 2 -fold bridge sites or 3-fold hollow sites. ${ }^{77}$ Since bonding motifs evolve from on-top and bridge structures for subnanometer clusters with nonbulk structures to 3-fold sites for larger fcc structures, the extrapolation of this latter bonding scheme to two-dimensional SAMs is thought provoking. The data above also, by implication of the interpretation made regarding the preferential bonding of the thiolate moiety at 3-fold-hollow sites on the MPC core, establish

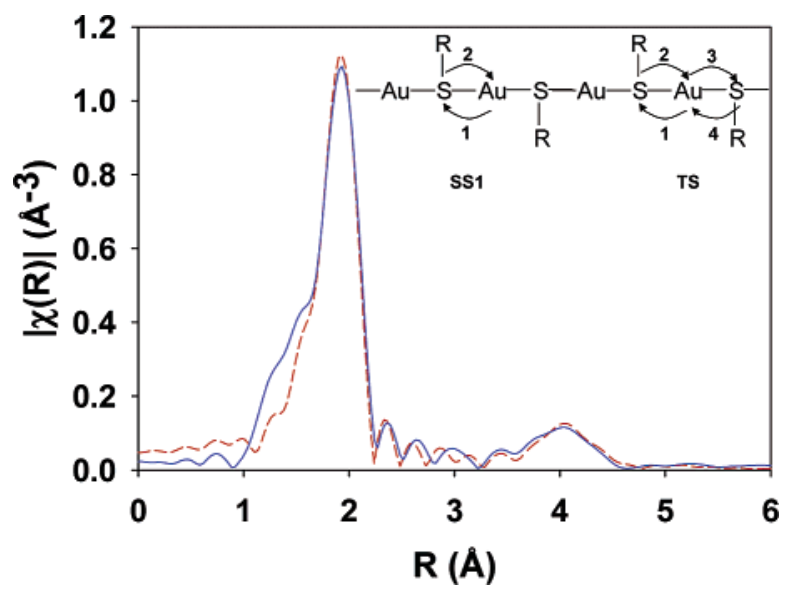

Figure 7. FT magnitude plots of the EXAFS data (solid blue line) and full multiple-scattering-path fit (dashed red line) for the gold(I) dodecanethiolate polymer. The inset diagram illustrates the singlescattering (SS1) and triple-scattering (TS) paths used in the fit. a likely composition of the average cluster in this sample. The values we estimate for the above correspond to clusters with an average formula of $\mathrm{Au}_{180}\left[\mathrm{~S}\left(\mathrm{CH}_{2}\right)_{11} \mathrm{CH}_{3}\right]_{40}$.

The EXAFS results for the Au MPCs present a picture of thiolate monolayers with structure similar to that of their twodimensional analogues. Recent reports have emerged, however, that propose a model unique to nanoparticles in which a $\mathrm{Au}$ core may be surrounded by a $\mathrm{Au}_{2} \mathrm{~S}$ shell upon which thiolates are bound. ${ }^{38,39}$ Our own studies suggested that the presence of a gold(I) thiolate species, due either to incomplete reduction during the synthesis or to sample degradation, may in fact account for some of the noted discrepancies. For this reason, we carried out one additional EXAFS study, an examination of a previously reported gold thiolate polymer species, the results for which are included as a cautionary note. ${ }^{47,78,79}$

The hyperbolic increase in coordination numbers with increasing metal cluster size presents EXAFS measurements with a nonstatistical (but rather mass-weighted) sensitivity toward smaller clusters or low-coordination organometallic species. ${ }^{18,24,33}$ In this context, the presence of a gold(I) thiolate species can lead to estimates suggesting both suspiciously high $\mathrm{Au}-\mathrm{S}$ and low $\mathrm{Au}-\mathrm{Au}$ scattering magnitudes. Figure 7 shows the Fourier-transformed data and fit $\left(k=3-15 \AA^{-1}, R=1-3\right.$ $\AA, k^{2}$ weighting) for a sample of a gold(I) dodecanethiolate polymer. The resulting fit parameters are displayed in Table 3 and show good agreement with the expected values for a linear polymer. The notable absence of any $\mathrm{Au}-\mathrm{Au}$ scattering contribution is suggestive of a large degree of disorder in the polymer chain.

We note that the spectrum of the above polymer is in most regards identical to those in earlier reports that were attributed to nanoparticles. ${ }^{38,39}$ The apparent disparity between the average particle size measured with electron microscopy $(d \approx 1.5 \mathrm{~nm})$ and the high $\mathrm{Au}-\mathrm{S}$ and low $\mathrm{Au}-\mathrm{Au}$ coordination numbers was explained by the adoption of a complex structure involving a $\mathrm{Au}$ core, $\mathrm{Au}_{2} \mathrm{~S}$ shell, and thiolate ligand structure that has no chemical precedent. ${ }^{38,39}$ In light of the results presented in this paper, a more reasonable explanation is the presence of the gold thiolate polymer as an impurity. While EXAFS is uniquely sensitive to this impurity, it remains an exceptionally difficult material to detect on the basis of TEM measurements (contrasts in this case are ones of essentially single-atom character). The interesting magnetic and electronic properties attributed to these samples should be reassessed in our view and a determination made whether they indeed result from nanoparticles or from other species. ${ }^{38}$

\section{Conclusions}

Quantitative HAADF-STEM and high-resolution TEM measurements were made on subnanometer gold clusters that indicate cluster cores of 13 atoms with average diameters of $0.8 \mathrm{~nm}$. The structures of these $\mathrm{Au}_{13}$ clusters are consistent with an icosahedral packing motif as determined by multiplescattering-path fitting analysis of the EXAFS spectra. The correlative use of electron microscopy and X-ray absorption spectroscopy is extended to thiolate-protected clusters that show a larger mean particle core diameter and a larger distribution in 
particle sizes. Comparisons between the two techniques show excellent agreement and indicate particle cores with bulklike fcc structure. The use of the two techniques is also valuable in providing information about the density of thiolate ligands on the surface of the gold nanoparticles, supporting a model where ligands bind at 3 -fold sites on the nanoparticle surface. The analysis of EXAFS measurements of a gold(I) thiolate polymeric species reveals a spectrum in most ways identical to spectra attributed to thiolate-protected nanoparticles in previous reports, a finding that suggests the presence of this polymeric species in the samples investigated in those earlier studies.

Acknowledgment. This work was sponsored in part by grants from the Department of Energy (DOE) (R.G.N., DEFG0203ER15476; A.I.F., DEFG02-03ER15477; J.C.Y., DEFG0203ER15475), the National Science Foundation (R.W.M.), and the Office of Naval Research (R.W.M.). Experiments were carried out at the Frederick Seitz Materials Research Laboratory at the University of Illinois at Urbana-Champaign, which is partially supported by the U.S. Department of Energy under Grant DEFG02-91-ER45439. Research was also carried out at the National Synchrotron Light Source at Brookhaven National Laboratory and at the Advanced Photon Source at Argonne National Laboratory. Use of the National Synchrotron Light Source was supported by the U.S. Department of Energy, Office of Science, Office of Basic Energy Sciences, under Contract No. DE-AC02-98CH10886. The UNICAT facility at the Advanced Photon Source (APS) is supported by the U.S. DOE under Award No. DEFG02-91ER45439, through the Frederick Seitz Materials Research Laboratory at the University of Illinois at Urbana-Champaign, the Oak Ridge National Laboratory (U.S. DOE Contract DE-AC05-00OR22725 with UT-Battelle LLC), the National Institute of Standards and Technology (U.S. Department of Commerce), and UOP LLC. The APS is supported by the U.S. DOE, Basic Energy Sciences, Office of Science, under Contract No. W-31-109-ENG-38. We acknowledge Paul Zschack and Jenia Karapetrova for their assistance in performing XAS experiments at the APS. L.D.M. thanks the Office of the Deputy Under Secretary of Defense for Science and Technology and the Army Research Office for support through an NDSEG fellowship.

\section{References and Notes}

(1) Nanoparticles: From Theory to Application; Schmid, G., Ed.; Wiley-VCH: Weinheim, Germany, 2004.

(2) Metal Nanoparticles: Synthesis, Characterization, and Applications; Feldheim, D. L., Foss, C. A., Eds.; Marcel Dekker: New York, 2002.

(3) El-Sayed, M. A. Acc. Chem. Res. 2004, 37, 326.

(4) Shenhar, R.; Rotello, V. M. Acc. Chem. Res. 2003, 36, 549.

(5) Chen, S.; Ingram, R. S.; Hostetler, M. J.; Pietron, J. J.; Murray, R. W.; Schaaff, T. G.; Khoury, J. T.; Alvarez, M. M.; Whetten, R. L. Science 1998, 280, 2098.

(6) Schmid, G. Chem. Rev. 1992, 92, 1709.

(7) Kruger, S.; Vent, S.; Nortemann, F.; Staufer, M.; Rosch, N. J. Chem. Phys. 2001, 115, 2082.

(8) Cleveland, C. L.; Landman, U.; Schaaff, T. G.; Shafigullin, M. N.; Stephens, P. W.; Whetten, R. L. Phys. Rev. Lett. 1997, 79, 1873.

(9) Haberlen, O. D.; Chung, S.-C.; Stener, M.; Rosch, N. J. Chem. Phys. 1997, 106, 5189.

(10) Li, J.; Li, X.; Zhai, H.-J.; Wang, L.-S. Science 2003, 299, 864.

(11) Treacy, M. M. J.; Rice, S. B. J. Microsc. 1989, 156, 211.

(12) Singhal, A. Quantitative Electron Microscopy of Supported Subnanometer Clusters. Ph.D. Thesis, University of Illinois at UrbanaChampaign, Urbana, IL, 1996.

(13) Singhal, A.; Yang, J. C.; Gibson, J. M. Ultramicroscopy 1997, 67, 191.

(14) Yang, J. C.; Bradley, S.; Gibson, J. M. Microsc. Microanal. 2000, $6,353$. 101.
(16) Narayanaswamy, D.; Marks, L. D. Z. Phys. D 1993, 26, S70.

(17) Wilcoxon, J. P.; Martin, J. E.; Provencio, P. Langmuir 2000, 16, 9912.

(18) Liu, J. Microsc. Microanal. 2004, 10, 55.

(19) Williams, D. B.; Carter, C. B. Transmission Electron Microscopy; Plenum Press: New York, 1996.

(20) Menard, L. D.; Gao, S.-P.; Xu, H.; Twesten, R. D.; Harper, A. S.; Song, Y.; Wang, G.; Douglas, A. D.; Yang, J. C.; Frenkel, A. I.; Nuzzo, R. G.; Murray, R. W. J. Phys. Chem. B 2006, 110, 12874.

(21) Hills, C. W.; Nashner, M. S.; Frenkel, A. I.; Shapley, J. R.; Nuzzo, R. G. Langmuir 1999, 15, 690 .

(22) Nashner, M. S.; Frenkel, A.; Adler, D. L.; Shapley, J. R.; Nuzzo, R. G. J. Am. Chem. Soc. 1997, 119, 7760 .

(23) Nashner, M. S.; Frenkel, A. I.; Somerville, D.; Hills, C. W.; Shapley, J. R.; Nuzzo, R. G. J. Am. Chem. Soc. 1998, 120, 8093.

(24) Frenkel, A. I.; Hills, C. W.; Nuzzo, R. G. J. Phys. Chem. B 2001, 105,12689 .

(25) Zhang, P.; Sham, T. K. Phys. Rev. Lett. 2003, 90, 245502.

(26) Benfield, R. E.; Grandjean, D.; Kroll, M.; Pugin, R.; Sawitowski, T.; Schmid, G. J. Phys. Chem. B 2001, 105, 1961.

(27) Koningsberger, D. C., Prins, R., Eds. X-Ray Absorption: Principles, Applications, Techniques of EXAFS, SEXAFS and XANES; John Wiley \& Sons: New York, 1988.

(28) Mansour, A. N.; Cook, J. W.; Sayers, D. E. J. Phys. Chem. 1984 $88,2330$.

(29) Samant, M. G.; Boudart, M. J. Phys. Chem. 1991, 95, 4070.

(30) Teo, B. K. EXAFS: Basic Principles and Data Analysis; SpringerVerlag: Berlin, 1986

(31) Nashner, M. S.; Somerville, D. M.; Lane, P. D.; Adler, D. L.; Shapley, J. R.; Nuzzo, R. G. J. Am. Chem. Soc. 1996, 118, 12964.

(32) Hills, C. W.; Mack, N. H.; Nuzzo, R. G. J. Phys. Chem. B 2003, $107,2626$.

(33) Frenkel, A. I. J. Synchrotron Radiat. 1999, 6, 293.

(34) Frenkel, A. I.; Nemzer, S.; Pister, I.; Soussan, L.; Harris, T.; Sun, Y.; Rafailovich, M. H. J. Chem. Phys. 2005, 123, 184701.

(35) Woehrle, G. H.; Warner, M. G.; Hutchison, J. E. J. Phys. Chem. B 2002, 106, 9979.

(36) Woehrle, G. H.; Hutchison, J. E. Inorg. Chem. 2005, 44, 6149.

(37) Yang, Y.; Chen, S. Nano Lett. 2003, 3, 75.

(38) Crespo, P.; Litran, R.; Rojas, T. C.; Multigner, M.; de la Fuente, J. M.; Sanchez-Lopez, J. C.; Garcia, M. A.; Hernando, A.; Penades, S.; Fernandez, A. Phys. Rev. Lett. 2004, 93, 087204.

(39) Lopez-Cartes, C.; Rojas, T. C.; Litran, R.; Martinez-Martinez, D.; de la Fuente, J. M.; Penades, S.; Fernandez, A. J. Phys. Chem. B 2004, 109,8761

(40) Keyse, R. J.; Garratt-Reed, A. J.; Goodhew, P. J.; Lorimer, G. W. Introduction to Scanning Transmission Electron Microscopy; SpringerVerlag: New York, 1998.

(41) Newville, M. J. Synchrotron Radiat. 2001, 8, 322.

(42) Newville, M.; Livins, P.; Yacoby, Y.; Rehr, J. J.; Stern, E. A. Phys. Rev. B 1993, 47, 14126 .

(43) Zabinski, S. I.; Rehr, J. J.; Ankudinov, A.; Albers, R. C.; Eller, M. J. Phys. Rev. B 1995, 52, 2995.

(44) Ishikawa, K.; Isonaga, T.; Wakita, S.; Suzuki, Y. Solid State Ionics $1995,79,60$.

(45) Citrin, P. H.; Eisenberger, P.; Kincaid, B. M. Phys. Rev. Lett. 1976, $36,1346$.

(46) Brust, M.; Waker, M.; Bethell, D.; Schiffrin, D. J.; Whyman, R. J. Chem. Soc., Chem. Commun. 1994, 7, 801.

(47) Templeton, A. C.; Wuelfing, W. P.; Murray, R. W. Acc. Chem. Res. 2000, 33, 27.

(48) Whetten, R. L.; Khoury, J. T.; Alvarez, M. M.; Murthy, S.; Vezmar, I.; Wang, Z. L.; Stephens, P. W.; Cleveland, C. L.; Luedtke, W. D.; Landman, U. Adv. Mater. 1996, 8, 428.

(49) Schaaff, T. G.; Whetten, R. L. J. Phys. Chem. B 1999, 103, 9394. (50) Alvarez, M. M.; Khoury, J. T.; Schaaff, T. G.; Shafigullin, M. N.;

Vezmar, I.; Whetten, R. L. Chem. Phys. Lett. 1997, 266, 91.

(51) Wang, Z. L. J. Phys. Chem. B 2000, 104, 1153.

(52) Smith, D. J.; Petford-Long, A. K.; Wallenberg, L. R.; Bovin, J.-O. Science 1986, 233, 872 .

(53) Barnett, R. N.; Cleveland, C. L.; Hakkinen, H.; Luedtke, W. D.; Yannouleas, C.; Landman, U. Eur. Phys. J. D 1999, 9, 95.

(54) Chang, C. M.; Chou, M. Y. Phys. Rev. Lett. 2004, 93, 133401.

(55) Bellon, P.; Manassero, M.; Sansoni, M. J. Chem. Soc., Dalton Trans. $1973,2423$.

(56) Laguna, A.; Laguna, M.; Concepcion Gimeno, M. Organometallics 1992, 11, 2759.

(57) Smits, J. M. M.; Beurskens, P. T.; Bour, J. J.; Vollenbroek, F. A. J. Crystallogr. Spectrosc. Res. 1983, 13, 365 .

(58) Albano, V. G.; Bellon, P. L.; Manassero, M.; Sansoni, M. Chem. Сотmun. 1970, 1210

(59) Bellon, P. L.; Cariati, F.; Manassero, M.; Naldini, L.; Sansoni, M J. Chem. Soc., Chem. Commun. 1971, 1423. 
(60) Teo, B. K.; Shi, X.; Zhang, H. J. Am. Chem. Soc. 1992, 114, 2743.

(61) Bellon, P. L.; Manassero, M.; Sansoni, M. J. Chem. Soc., Dalton Trans. 1972, 1481.

(62) CRC Handbook of Chemistry and Physics, 75th ed.; Lide, D. R., Ed.; CRC Press: Boca Raton, FL, 1994.

(63) Mattheiss, L. F.; Dietz, R. E. Phys. Rev. B 1980, 22, 1663.

(64) Zhang, P.; Sham, T. K. Appl. Phys. Lett. 2002, 81, 736.

(65) Wagner, C. D.; Riggs, W. M.; Davis, L. E.; Moulder, J. F.; Muilenberg, G. E. Handbook of X-Ray Photoelectron Spectroscopy; PerkinElmer Corp.: Eden Prairie, MN, 1979.

(66) Thomanny, A. L.; Braulty, P.; Rozenbaumy, J. P.; AndreazzaVignollez, C.; Andreazzaz, P.; Estrade-Szwarckopfz, H.; Rousseauz, B.; Babonneaux, D.; Blondiauxk, G. J. Phys. D: Appl. Phys. 1997, 30, 3197.

(67) Chusuei, C. C.; Lai, X.; Luo, K.; Goodman, D. W. Top. Catal. 2001, 14, 71.

(68) Fritsche, H.-G.; Buttner, T. Z. Phys. Chem. 1999, 209, 93.
(69) Mackay, A. L. Acta Crystallogr. 1962, 15, 916

(70) Fritsche, H.-G.; Benfield, R. E. Z. Phys. D 1993, 26, S15.

(71) Baenziger, N. C.; Bennett, W. E.; Soboroff, D. M. Acta Crystallogr. 1976, $B 32,962$.

(72) Mingos, D. M. P. J. Chem. Soc., Dalton Trans. 1996, 561.

(73) Jaw, H.-R. C.; Mason, W. R. Inorg. Chem. 1991, 30, 3552.

(74) Briant, C. E.; Hall, K. P.; Wheeler, A. C.; Mingos, D. M. P. J. Chem. Soc., Chem. Commun. 1984, 248.

(75) Hostetler, M. J.; Murray, R. W. Curr. Opin. Colloid Interface Sci. 1997, $2,42$.

(76) Daniel, M.-C.; Astruc, D. Chem. Rev. 2004, 104, 293.

(77) Love, J. C.; Estroff, L. A.; Kriebel, J. K.; Nuzzo, R. G.; Whitesides, G. M. Chem. Rev. 2005, 105, 1103.

(78) Corbierre, M. K.; Beerens, J.; Lennox, R. B. Chem. Mater. 2005, 17, 5774 .

(79) Corbierre, M. K.; Lennox, R. B. Chem. Mater. 2005, 17, 5691 